\title{
On Data Portraits: An analysis of creative approaches to the visualisation of personal data
}

\author{
Catarina Sampaio \\ University of Lisbon, Faculty of Fine \\ Arts, Centro de Investigação e de \\ Estudos em Belas-Artes (CIEBA) \\ Lisbon, Portugal \\ hello@catarinasampaio.com
}

\author{
Luísa Ribas \\ University of Lisbon, Faculty of Fine \\ Arts, Centro de Investigação e de \\ Estudos em Belas-Artes (CIEBA) \\ Lisbon, Portugal \\ l.ribas@belasartes.ulisboa.pt
}

\begin{abstract}
The portrait, as a symbolic representation of personal identity, tends to reflect the social, cultural and technical context in which it is created. At a moment where technological mediation is omnipresent, data portraits appear as forms of portraiture that evocatively represent the identity of individuals based on the visualisation of their personal data, resulting from their daily activities that are digitally registered by technological devices of everyday use. This paper discusses the conceptual and creative possibilities associated with the concept of data portrait, through the description and analysis of artefacts that imply this notion. In order to understand the diversity of these artefacts, we propose a framework for their analysis focused on their concepts, mechanics and on the elements of their experience. In particular, we address their expressive functions, the types of data sources they use and how that data is collected. We then consider the data visualisation processes involved and, finally, describe the resulting sensory manifestations. By focusing on these forms of portraiture, as devised with the aid of computational means, this analysis also reflects on how portraiture can be reconceptualised to become more attuned with our contemporary mode of living immersed in data.
\end{abstract}

Personal data. Data portrait. Data visualisation. Identity. Computational media.

\section{INTRODUCTION}

The use of digital tools, such as smartphones, personal computers, mobile cameras, online platforms, mobile apps and wearable devices, enables the tracking of various aspects of human life as quantified data. This can comprise large sets of personal information pertaining to actions, habits and preferences, social relationships, as well as bodily functions and movements (Lupton 2020). As expressed by Wolf (2010), "numbers are infiltrating the last redoubts of the personal. Sleep, exercise, sex, food, mood, location, alertness, productivity, even spiritual well-being, are being tracked and measured, shared and displayed". This tendency towards quantification is becoming widespread, as technologies become cheaper, smaller, wearable, and increasingly unnoticed while collecting personal data. Therefore, personal narratives can now arise from multiple layers of measurable quantified data.

This paper is part of an ongoing research that reflects on our current "data-driven [way of] life"
(Wolf 2010) and the prevailing trend to quantify of all aspects of human life. It seeks to highlight how data portraits become relevant as an expression of personal identity and how the construction of identity can, in turn, be informed by these data mediations, as tools for self-representation, selfunderstanding and self-government.

\section{PORTRAITURE AND THE REPRESENTATION OF IDENTITY}

Portraiture has been the preferred cultural means of conveying personal identity, be it through cues embedded in the setting or in the human figure (Borgatti 2008). The portrait can be regarded as an aesthetic construction that intends to symbolically represent individuals, not only depicting their physical characteristics but also psychological states, social status and even ideologies. The portrait then aims to visually denote the particular characteristics of a certain person, such as their emotions, experiences, behaviours or even knowledge (West 2004, p.21). In Western culture, it traditionally resorts to lifelike images of the face as 
signifier due to its cognitive richness. As Donath (2001) points out, the face briefly and at a glance conveys the subject's identity in terms of gender, race, age, as well as mood states and the effects of facial expressions cumulatively repeated.

When the dissemination of photography freed artistic production from a mimetic function, the portrait adopted more conceptual approaches, detaching itself from the representation of the physical body and moving towards formal abstraction. For example, Portrait of Deb from 1988-199? (2012-2013) by L. J. Roberts, results from a series of embroidered emblems collected by Deb, as the outcome of an autoethnographic practice. The work is based on the notion that material objects express meaning and employs enumeration techniques and personal inventory as a form of portraiture (Goodyer and al. 2016, p.240). Another example would be Everyone I Have Ever Slept With 1963-1995 (1995), by Tracey Emin, which is an art installation composed of a tent with the appliquéd names of, literally, everyone she had ever slept with, including family, friends, lovers and even two numbered foetuses (West 2004, p.211).

These approaches correspond to an exploration of identity that shifts "attention from the iconic qualities of portraiture to the indexical ones" (West 2004, p.212). According to Van Alphen (2004, p.250), iconic representations refer to their subjects mimetically to make that person present, while indexical portraits don't claim presence; they evoke it in referential terms. This semiotic shift from the icon to the index thus provides a conceptual ground for the emergence of data portraits as a form of portraiture attuned to our increasingly digitalised way of life, where almost every human activity leaves a trace of data.

\section{DATA PORTRAITS AS REPRESENTATIONS OF IDENTITY THROUGH DATA}

The first notable experiences around data portraits emerged in the late 1990s, to represent participants in online forums. Visualisations were created to map each user's activity and help group members "make sense of each other" (Donath 2017, p.198). The PeopleGarden (1999) project was one of the first data portraits created at MIT. It used the "simplicity and intuitiveness" of the garden metaphor to convey how user behaviour changed over time" (Xiong and Donath 1999).

The notion of data portrait then refers to forms of portraiture that evocatively represent one's identity as "depictions of people made by visualising data by and about them" (Donath 2017, p.187). So, these portraits do not represent faces, instead, their visuality is the product of the quantification and visualisation of data produced in the course of daily experiences and registered by technological devices of everyday use.

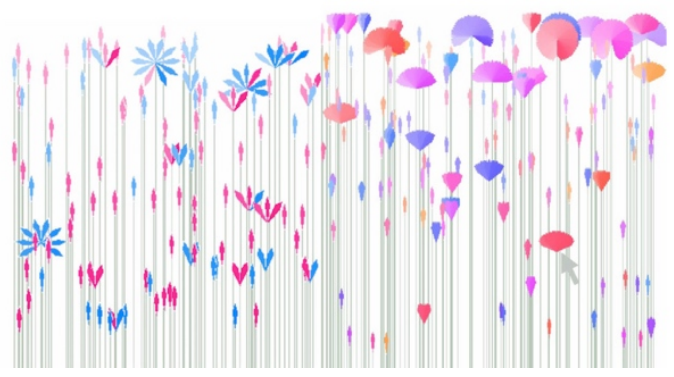

Figure 1: PeopleGarden, R. Xiong \& J. Donath, 1999

This appropriation of techniques from the scientific disciplines, such as the exhaustive observation of daily life, data collection, analysis and inventory, can be regarded as an ethnographic basis for the production of aesthetic artefacts (Morley 2007, p.100). Each set of data is a record of human activity, meaning that "behind every text or number list lies a story, experience, feeling, or interaction". Following this idea, "visualising data in a graphical format is an important and powerful way of relating ideas, experiences and stories of human interaction that may otherwise go untold or unseen" (Richardson 2016, p.162).

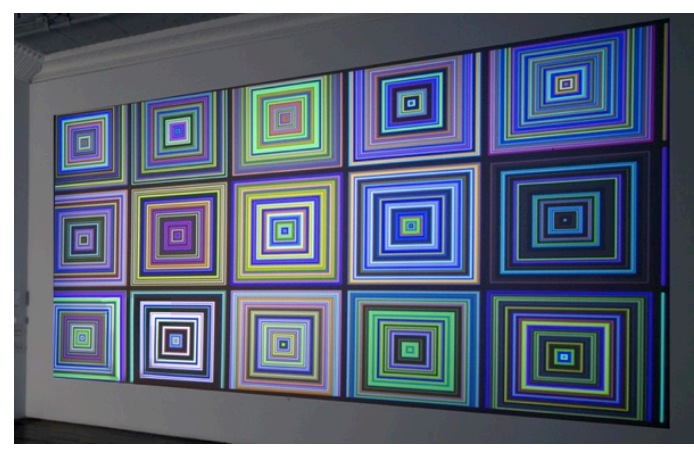

Figure 2: Spigot (Babbling Self-Portrait), Salavon, 2010

Although different from traditional portraits, data portraits evoke the same functions of their classic counterparts, as essentially tied to the representation of the subject before the other and/or before himself. On one hand, they can act as proxies of individuals in online communities, revealing their behavioural patterns, rather than appearance. On another hand, data portraits can act as a "data mirror", or a "portrait designed to be seen only by the subject, as a tool for selfunderstanding" (Donath et al. 2014). Additionally, and by involving the re-appropriation of personal data that is scattered in a variety of distributed networks, data portraits can also fulfil a political role by drawing attention to the loss of control over private information. Finally, these portraits can also promote an affective tie with one's personal data, as an effect of its instantiation and due to its biographical qualities (Lupton 2016). 


\section{ANALYSIS FRAMEWORK}

In order to provide an overview of the creative approaches that are tied to the notion of data portrait, we analysed a set of aesthetic artefacts that: 1) address the visual representation of personal identity, 2) use personal data as a raw material, resulting from the subject's daily activities or bodily functions, and thus 3) resort to computational means for collecting, analysing and visualising data:

1. PeopleGarden, Rebecca Xiong \& Judith Donath, 1999

2. Authorlines, Fernanda Viégas \& Marc Smith, 2004

3. DNA Portraits, DNA11, 2005

4. Spigot (Babbling Self-Portrait), Jason Salavon, 2010

5. TimeMachine, CADA, 2012

6. Mood + Quantify, Laurie Frick, 2011-2013

7. Heart Bot, Odd Division, 2014

8. Data as Object, Brendan Dawes, 2014

9. The Art of the Thrill, Sosolimited, 2014

10. Walking, Laurie Frick, 2012-2015

11. Data Portraits, Kristin Mclver, 2015

12. The Sixth Sense, Clever Franke, 2016

13. Poisonous Antidote, Mark Farid, 2016

14. Floating Map, Stephan Cartwright, 2016

15. Heart of Travel, Joshua Davis, 2017

16. Halo, Peter Crnokrak - ORA, 2017

17. The Art of Feeling, Random Quark, 2017

The analysis focuses on the concepts behind these aesthetic artefacts, considering how the choice of personal data defines the theme and content of the data portrait. We then pay attention to their mechanics, considering the means of data collection and also to the data analysis processes. Finally, we observe the elements of the experience of each work, namely the resulting visualisation, or what is made accessible for the audience to experience in terms of surface and dynamics (Ribas 2014).

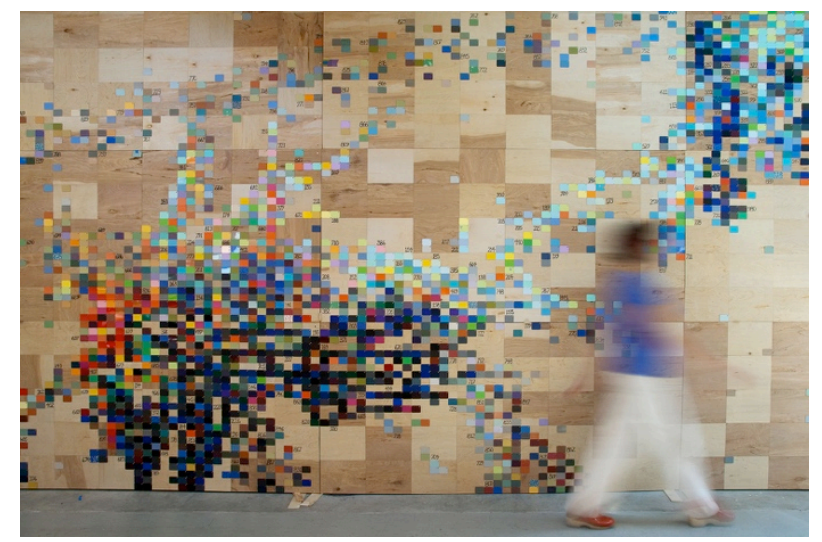

Figure 3: Mood + Quantify, L. Frick, 2011-2013
The adopted framework is also informed by the notion of a "digital informational praxis", as discussed by Renaud (2003), that pertains to data collection, its symbolic structuration at a logicalmathematical level and its visual representation, which constitutes an "informational image". This analysis can also be coupled with the methods for understanding data purposed by Fry $(2008$, p.5, 6), as implying the obtention of data (acquire), structuring them (parse), the usage of methods of quantitative analysis such as statistics (mine), the representation of data according to a visual model (represent), the refinement of the representation in order to make it clear and visually appealing (refine) and, finally, the integration of interactive features that allow viewers to select data and control how it is displayed (interact).

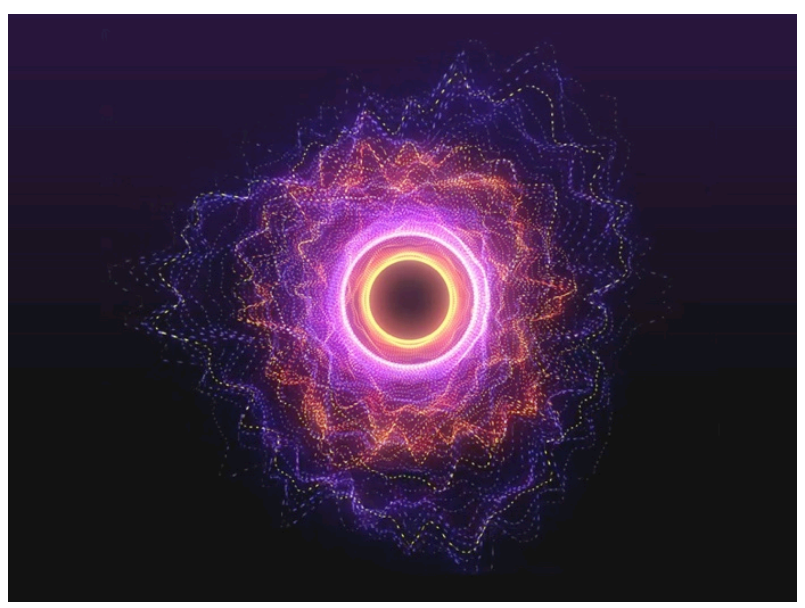

Figure 4: Halo, P. Crnokrak - ORA, 2017

Regarding the works' concepts and concerning to its theme, the portrait's intent is tied to the main functions of the data portraits, either as proxies, as mechanisms of self-observation through selftracking, or as means of re-appropriating personal data scattered in several networks and platforms. We also distinguish a self-portrait from an individual or a collective portrait, as well as the motivation for its production, as exploratory, reflective or critical (artistically driven) or applied to a product or service (commercially driven). Regarding the kind of personal data used as content for these visualisations, we consider how the identity of the subject is expressed. To this end, we take into account how Whitehead (2005) discusses the ethnographic value of the various types of personal data, relating to physical or psychological characteristics of the individual, their social relationships, behavioural patterns or pertaining to their physical environment. We then resort to the taxonomy purposed by Freeman et al. (2016) distinguishing between biometrical data, data related to subject's actions, or data pertaining to subject's surroundings. 
Concerning the mechanics of data portraits, the data collection can be done by means of service providers when using digital network services (big data), by devices with built-in sensors (IoT) or data can also be provided by the user through social networks and other platforms (web 2.0), being that the resulting data formats are, in most cases, textual, or numeric. The data collection process can, according to Selke (2016), be active (if the individual actively collects the data, often manually) or passive (when they are automated by technological devices). The passive methods can either be deliberate (if one decides to use selftracking devices to gather personal data, such as sensors, or apps that extract personal data from big data clouds) or non-deliberate (when collected by third parties, often without one's awareness). We also address the processes of data analysis implied in the production of data portraits, highlighting when statistical analysis is applied to personal data. Finally, we observe how the mapping process is done, either manually or in an automated way.

The experience dimension contemplates the sensory expression and observable behaviour of the portrait. Concerning its surface, we observe the type of informational structure employed in the visualisation according to the categories defined by Meirelles (2013), which can be hierarchical, relational, temporal, spatial, spatio-temporal or textual. Additionally, the representational stance of the visualisation can be analytical (and the visualisation favours legibility) or only legible via interaction, but it can also be expressive (when the visualisation favours a subjective experience, such as introspection, surprise or aesthetic enjoyment). The modes of expression of these artefacts can be either visual, audio-visual or material. The output format of the visualisation system can be images, objects, videos, online interfaces (or apps), or installations (or performances). Regarding the dynamics of the portrait, its output can be either static, transient (time-based) or variable (in realtime). The overall behaviour of the visualisation system can be merely contemplative or allow interactive exploration.

\section{ANALYSIS RESULTS}

\subsection{Concepts: approaches to personal data}

Different approaches to personal data can correspond to the diverse intents or functions of data portraits, revealing how their theme is shaped by the data they resort to (Figure 5).

Many of the works analysed aim at representing individuals before themselves, acting as selfportraits or tools for self-observation by means of self-tracking. As such they can be described as "technologies of the self", according to Foucault (1998), or as tools of self-regulation, considering that technologies can encompasses all extensions of human capabilities. "Technologies of the self" are then mechanisms "which permit individuals to effect (...) a certain number of operations on their own bodies and souls, thoughts, conduct, and way of being, so as to transform themselves" (Foucault 1988, p.18). Data portraits like Halo (2017) and

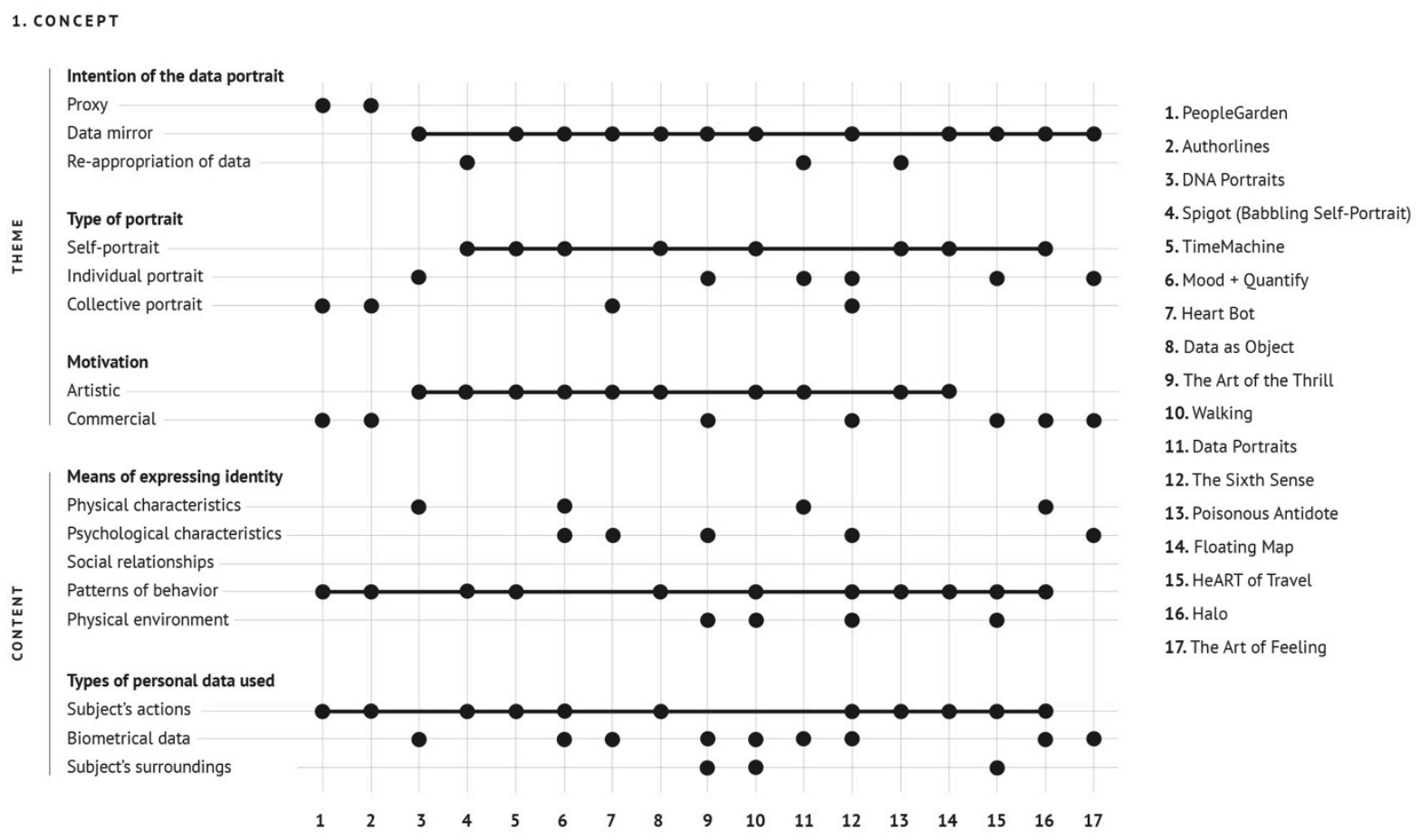

Figure 5: Analysis results of the conceptual dimension of data portraits 
TimeMachine (2012), or Data as Object (2014) can be regarded as mechanisms of self-observation that use computational technologies to highlight patterns arising from personal data, thus enabling self-governance through data.

Other individual portraits fulfil a political role, pertaining to the aggregation and re-appropriation of personal data that is scattered on different networks and platforms, often not accessible to the individuals who produce it. Such is the case of Spigot (Babbling Self-Portrait) (2010) or Poisonous Antidote (2016). Both resort to big data and highlight aspects related to privacy and security, by raising questions about who owns our personal data. Poisonous Antidote, publicly presented the author's e-mails, messages, phone calls, browsing history, location coordinates, social media posts, as well as any photographs or videos on his phone. These data were fed to a 3D printer, creating an abstract sculpture in which each layer represents a day of the artist's 'digital life'. These kinds of portraits are often pieces of speculative design presented in an artistic context. In turn, individual portraits resulting from self-tracking usually have a functional purpose and are conceived as services or products, thus following a commercial motivation.

On the other hand, collective portraits often function as online 'proxies' of individuals, having an impact on how others act towards them. These portraits usually track behavioural patterns of the individual in online communities, hindering deceitful self-representation (Donath 2007). Such is the case of Authorlines (2004). Additionally, collective portraits can also highlight how people react differently in the same external circumstances, as in Heart Bot (2014) and The Sixth Sense (2016).

Most data portraits seek to reveal the subject's patterns of behaviour and/or psychological characteristics. They can use data related to one's actions or biometrical data, which allows us to infer psychological characteristics of the individual. For example, The Art of Feeling (2017) uses EEG signals to detected if the person is feeling positive or negative emotions, and The Art of the Thrill (2014) measures the thrill that one feels when driving a sports car in a racetrack by measuring heart rate, breathing, transpiration and body temperature. We also observed that some projects only resort to one type of data while others correlate various types in order to express different aspects of the subject's experience.

\subsection{Mechanics: data collection and analysis}

Considering the mechanics of data portraits, we can distinguish different methods of data collection as well as different forms of processing data, pertaining to the preliminary states of the development of a visualisation system (Figure 6).

We noticed that data is often collected by means of self-tracking, meaning in a passive but deliberate way, like in Walking (2012-2015) or Floating Map (2017), expressing the intentional incorporation of computational technologies in the collection and archiving of data related to aspects of a person's daily life (Selke 2016, pp.1-3). Personal data is also collected in a non-deliberate way, mainly when the aim of the portrait is to highlight the loss of control over our private information. For example, Spigot (Babbling Self-Portrait) (2010) uses data

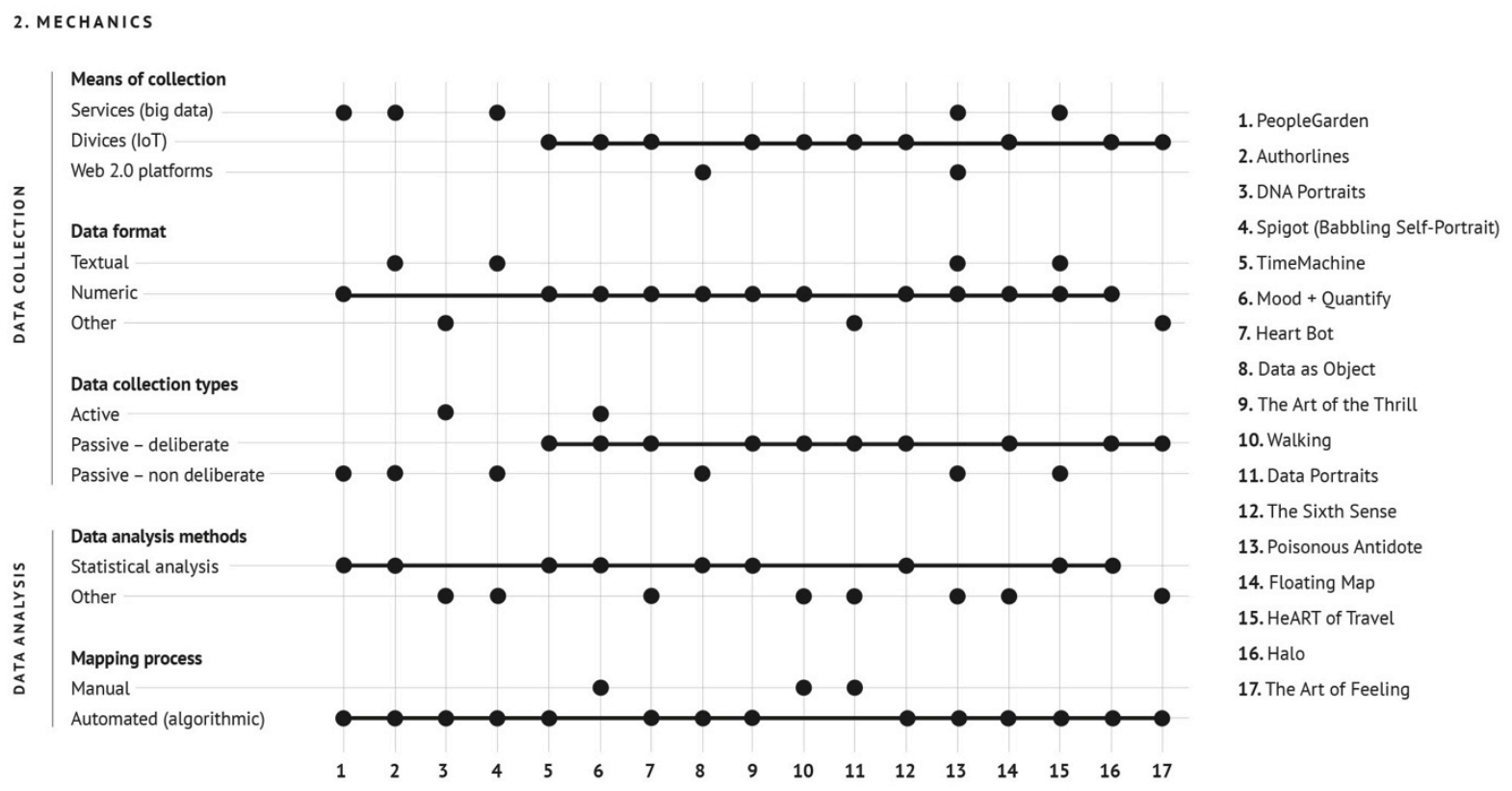

Figure 6: Analysis results of the mechanics dimension of data portraits 
from Salavon's browser search history, which Google keeps in file and mostly uses to build consumer profiles.

Considering the methods of data analysis, we notice that most projects resort to statistical analysis. They rely on the quantification of personal data in order to generate knowledge about the self, thus quantifying various aspects of the individuals' daily experiences to promote self-analysis. On the other hand, projects where statics are not applied, like Data Portraits (2015), which translates data collected by facial recognition technology into geometric paintings, tend to highlight the creative possibility of mapping or translating "anything" into "anything else" (Whitelaw 2008).

Given that our selection privileges computational data portraits, the mapping processes tend to be automated, thus the "actual data portrait is rendered by the intermediary mechanical artist, [meaning] a program or a collection of programs, that materialise the will of the artist/programmer" (Dragulescu 2009). Still, some projects rely on manual mapping processes, like in Mood +
Quantify (2011-2013) which is a visual record of how the artist feels, including stress levels, mood and biofunctions that are digitally recorded but physically represented.

\subsection{Experience: visualisation and expression of data}

The analysis reveals the diversity of modes of expression and formal aspects of data portraits, as well as their specific approaches to the visualisation of personal data (Figure 7).

At the level of their surface, most of the projects analysed use hierarchical, temporal, or spatiotemporal informational structures. The temporal dimension is highlighted in order to express the variable nature of human experience over time. As an example, Floating Map (2016), which is part of the Latitude and Longitude Project (ongoing since 1999), documents the author's position on the Earth's surface every hour of the day, representing that data through physical accumulation. The result is an object composed of overlapping layers that express the variation of data over time.

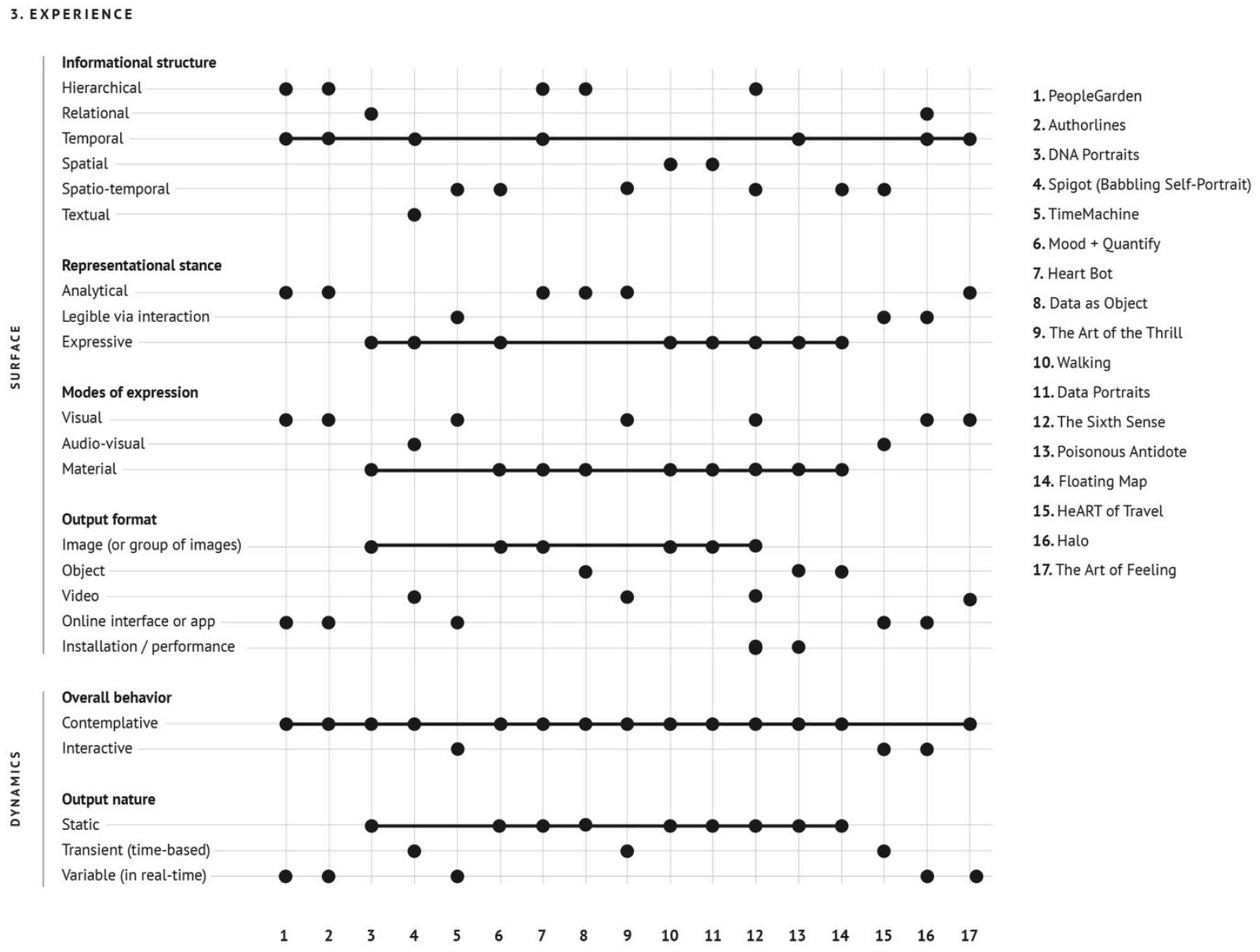

Figure 7: Analysis results of the experience dimension of data portraits 
In spite of using common information structures for data visualisation, most data portraits privilege expressiveness over legibility. When the visual outcome is abstract, it is distanced from an analytical stance concerned with legibility, favouring a subjective expression and promoting a contemplative experience. Even if "the goal of visualisation is often accuracy" as a tool for scientific or sociological analysis, the data portrait can also be "an artistic production, shaped by tension among the often-conflicting goals of the subject, artist and audience" (Donath 2017, p.187).

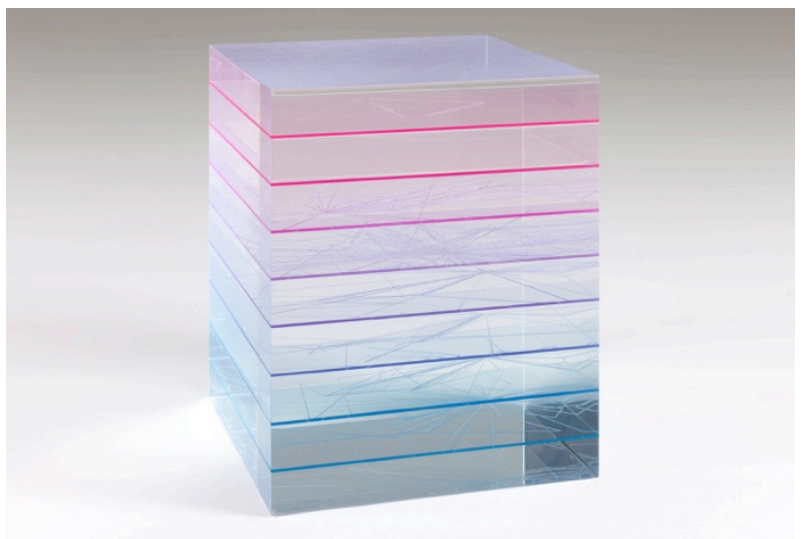

Figure 8: Floating Map, S. Cartwright, 2016

Although digitally produced, most data portraits have a material output, be it a printed image or, less frequently, a physical object, which can be presented in installation or performance formats. Dynamic output formats, like videos or online interfaces or apps, are also frequent, such as in TimeMachine (2012) and HeART of Travel (2017), which can be interactively explored. In terms of modes of expression, all projects privilege the visual modality (only twice complemented with sound).

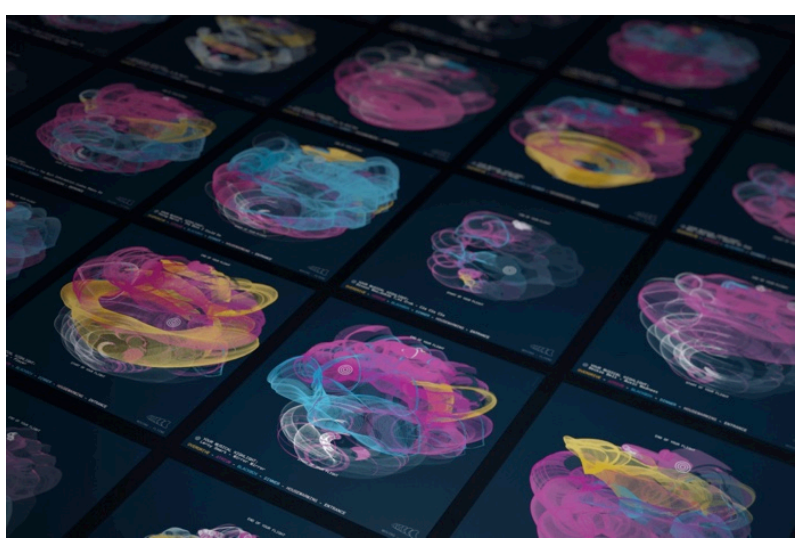

Figure 9: The Sixth Sense, Clever Franke, 2016

Concerning their dynamics, some data portraits often result in a static output complemented with a time-based visualisation. For example, The Sixth Sense (2016) used biometric data, movement and position of each participant of an electronic music event, which were mapped in real-time and projected on screens, allowing the sharing of each person's personal experience. Each participant was also presented with a printed visualisation, summarising their experience of at the event.

A static visualisation can then evoke aspects of traditional portraiture, such as the crystallisation of a moment in time, which is materialised for future contemplation. In contrast, dynamic visualisations are evolving self-portraits that unfold in real-time, seeking to highlight the changing nature of human experience.

\section{DISCUSSION AND CONCLUSION}

Data portraits prioritise aspects of identity "that are not directly observable" relating to actions, behaviours and ideas, as "socially relevant information that cannot be directly deduced from appearance" (Donath 2001). Therefore, they are tied to a cultural and ideological shift in the representation of identity, wherein appearance gradually loses its significance to the expressive potential of data as a raw material for portraiture.

Accordingly, although data portraits are basically based on numbers, or quantitative, abstract, and algorithmically generated, they have the ability to evoke individuality in ways that are not (completely) accessible to traditional forms of portraiture. In particular, by mapping human experience over time, they can express the fluid nature of identity, as it is shaped by the continuous flows of information that we create and are exposed to.

Even if a number of data portraits rely on methods of statistical analysis, they favour a subjective expression over the legibility of data, emphasising their subjective nature as forms of portraiture. In this sense, data portraits can be seen as visualisations of subjectivity but are also subjective visualisations, regarding design choices on what is to be represented, and how, as well as to what end or expression. These artistic forms of visualisation then "call into question the claims of transparency, certainty, and objectivity" of data visualisation, insisting in "the situatedness of the observer and the phenomenon being observed" (Hall 2011).

Adding to this idea, data portraits can also promote a reconceptualisation of portraiture as a representation genre more attuned to the current proliferation of digital data and to the creative possibilities of computational media. This kind of exploration of personal identity thus becomes increasingly relevant as a reflection of our contemporary mode of living immersed in data. 
In this context, data portraits can act, both, as an instrument for self-understanding and selfgovernance though data, but also a means to raise awareness on the implications of pervasive data collection. They can be a means to better understand ourselves and others, but also a way of raising questions about the role that technologies play in our daily lives, constantly capturing data in ways that often escape our awareness or control.

In conclusion, as proposed by Bill Viola (2003, p.469), "the development of the self must precede the development of technology or we will not go anywhere". So, perhaps we should turn back to ourselves to understand our role as the main drivers of technology, reflecting on the different modes of operation and motivations that guide our data driven lives.

\section{ACKNOWLEDGMENTS}

Este trabalho é financiado por fundos nacionais através da fct - fundação para a ciência e a tecnologia, i.p., no âmbito do projeto «uidb/04042/2020».

\section{REFERENCES}

Borgatti, J. M. (2008) Constructed Identities: Portraiture in World Art. In Zijlmans, K. (ed.) World Art Studies, Leiden Art History Yearbook V.14. Leiden, Primavera Press. pp.303-324.

Donath, J. (2001) Mediated Faces. In Beynon, M., Nehaniv, C.L. and Dautenhahn, K. (eds.) Cognitive Technology: Instruments of Mind, Volume 2117. 4th International Conference, CT 2001 Coventry, UK, August 6-9, 2001. pp.373-390.

Donath, J. (2007) Signalling Identity. http://smg.media.mit.edu/papers/Donath/SignalsTruthDe sign/SignalingAbstracts.1.pdf (retrieved 5 January 2020)

Donath, J. (2017) The Social Machine - Designs for Living Online. Massachusetts, MIT Press.

Donath, J., Dragulescu, A., Zinman, A., Viégas, F. Xiong, R. and Assogba, Y. (2010) Data Portraits. Leonardo. 43.

Dragulescu, A. (2009) Data Portraits: Aesthetics and Algorithms. Master thesis. Massachusetts Institute of Technology.

Foucault, M. (1988) Technologies of the Self. In Martin, L. H., Gutman, H. and Hutton, P. H. (eds.) Technologies of the self: A seminar with Michel Foucault. Amherst, The University of Massachusetts Press. pp.16-49.

Freeman J., Wiggins, G., Starks G. and Sandler M. (2018) A concise taxonomy for describing data as an art material. Leonardo. vol. 51. pp.75-79.
Fry, B. (2008) Visualizing Data. Sebastopol, CA: O'Reilly Media, Inc.

Goodyear, A. C., Walz, J., Campagnolo, K. and Evans, D. (2016) This Is a Portrait If I Say So: Identity in American Art, 1912 to Today. Yale, Yale University Press.

Hall, P. (2011) Bubbles, Lines, and Strings: How Information Visualization Shapes Society. In Blauvelt, A. and Lupton, E. (eds) Graphic Design: Now in Production. Minneapolis, Walker Art Center. pp.170-185.

Lupton, D. (2016) You are Your Data: Self-Tracking Practices and Concepts of Data. In Selke, S. (Ed.) Lifelogging: Digital Self-tracking and Lifelogging Disruptive Technology and Cultural Transformation. Berlin, Springer VS. pp.61-79.

Lupton, D. (2020) Data Selves More-than-Human Perspectives. Cambridge, Polity Press.

Meirelles, I. (2013) Design for Information. Massachusetts, Rockport Publishers.

Morley, D. (ed.) (2007) Media Modernity and Technology - The Geography of the New. New York, Routledge.

Renaud, A. (2003) L'interface informationnelle ou le sensible au sens de l'intelligible. In Poissant, L. (ed.), Esthétiques des Arts Médiatiques, Interfaces et Sensorialité. Québec, Presses Universitaires du Québec. pp.65-89.

Ribas, L. (2014) Digital Computational Systems as Aesthetic Artifacts: Practices, Systems, Processes and Perspectives. 2nd xCoAx International Conference on Computation, Communication, Aesthetics \& X. Porto, 26-27 June 2014.

Richardson, A. (2016) Data-Driven Graphic Design Creative Coding for Visual Communication. London and New York, Bloomsbury.

Selke, S. (2016) Lifelogging: Digital Self-tracking and Lifelogging - Disruptive Technology and Cultural Transformation. Berlin, Springer VS.

Van Alphen, E. (1997) The Portrait's Dispersal: Concepts of Representation and Subjectivity in Contemporary Portraiture. In Woodall, J. (ed.) Portraiture: Facing the Subject. New York, Manchester University Press.

Viola, B. (1982) Will There Be Condominiums in Data Space? In Wardrip-Fruin, N. (ed.) The New Media Reader. 2003. Massachusetts, MIT Press.

West, S. (2004) Portraiture. Oxford, Oxford University Press.

Whitehead, T. (2005) Basic Classical Ethnographic Research Methods. Maryland, University of Maryland.

Whitelaw, M. (2008) Art Against Information: Case Studies in Data Practice. In Hutchison, A. and Richardson, I. (eds.) The Fibreculture Journal. Issue 11.

Wolf, G. (2010) The Data-Driven Life. In The New York Times, 2 April 2010.

Xiong, R. and Donath, J. (1999) PeopleGarden: Creating Data Portraits for User. In 12th Annual ACM symposium on user interface software and technology. New York, USA. 